\title{
Study on Arts Teaching under New Media Environment
}

\author{
Fan Kang ${ }^{a, \star}$, Yingyan Chen, Yangang Zhou \\ Wuhan Polytechnic University, Wuhan, China \\ aKangfan2004@163.com
}

\begin{abstract}
This paper intends to use the concept of new media as an entry point, and through analyzing current educational situation of arts curriculum to explore the interactive course of and arts and its practical application. It broke the limitations of textbooks and teachers, thus highlighted the flavor of life and age in art curriculum.
\end{abstract}

Keywords: New media; Art curriculum; New Media Environment.

\section{Introduction}

New media is the product of information development society. Being faced with tremendous changes in media sphere, teaching resource construction was exposed to changes and challenges. New media technology, represented by network media, mobile phone media, digital television, with the concept and scale of application has brought profound impact on every aspect of social development and has became a hot topic for research. New media technology's application on education provided teaching resource construction with new possibility and proposition for development. Therefore, it is imperative to research and examine new media to reconsider and re-define relevant issues for the purpose of clearer, more precise study.

\section{New Media Conceptual Definition}

The term "new media" was coined in the 1960s, and only witnessed rapid development in recent decades limited by level of technological development. The concept of new media was put forward opposing to traditional media, and used to describe the communication pattern which adopting digital information technology to provide customers with entertainment and information service via various networks, communication channels, terminal devices such as computers, digital television and mobile phones. It is a new media format comes with technological development in information era. With the improvement of age, new media continues to enlarge its scale. As in table 1.

Table 1. New Media and Content of Communication

\begin{tabular}{cc}
\hline Forms of New media & Communication content \\
\hline Mobile TV & News, MTV, entertainment, arts, film, etc. \\
Graphics and Text TV & Communication Bank, tourism, weather \\
Mobile information & information, advertising, etc. \\
Interactive TV & News, information, video, advertising, etc. \\
Network broadcasting television & News, MTV, on demand, advertising, etc. \\
Network games & News, variety shows, special topics, TV \\
TV in Building & movies, advertising, etc. \\
Software communication & Online games, advertising, etc. \\
Blog, micro blogging, QQ & Commercials, etc. \\
\end{tabular}

New media's information propagation is both public and popular, at the same time individualistic and reified. It can dispel the borders between information disseminators and audiences and achieve seamless communication. Comparing to the traditional four medium: outdoors, newspapers and periodicals, broadcast, television, new media with its reproducibility, mobility and interactivity was also called the fifth media. It also brought the sense of immersion and hyperlink experience to 
audiences, and therefore caused qualitative transformation in media history which in turn give new media a highly competitive edge.

Moreover, the concept of new media is multi-dimensional for its existence beyond a mere advanced technology. The definition can be expanded to interpret from aspects of man-machine interface, division of industries, art movement and its multimedia forms when new media combined with different fields such as technology, industries, art, mass media etc. Simultaneously, new media gained more openness and liberty for ridding itself of material limitations.

The relationship between new media and traditional media is of inheritance and improvement, and of integration. Traditional media can transferred to new media with the help of digital technology, and new media then become mainstream media. Environment would influence any kind of information communication. Sharing content, channel confluence and media convergence is the new trend. Technical form, media form and communication pattern constitutes new media structure. It is the key to pinpoint the informational environment and media-scape of teaching resources; the significant premise to seek ways of teaching resource construction and planning teaching resource development space; and basic condition for setting up teaching resource platform.

\section{Arts Interactive Teaching under New Media Environment}

\subsection{Classroom Interactive Teaching Using New Media as Auxiliary System}

Under new media education environment, arts interactive teaching mainly perform between teacher, students and media through "language interaction", "action interaction", "affective interaction" generated by specific scenario and teaching activities, then finally achieve "thinking interaction". In terms of time, interactions in new media classroom generally are real-time exchanges. More specifically, entity structure elements of classroom interaction supported by new media include: Learner, teaching community (teachers or other tutorship), media environment, teaching information. Teaching information and other three elements' relationships while in other three elements or occurring during interaction are shown in Figure 1. It is clear that entity interactive elements are main bodies of classroom interactive teaching. Through competitive interaction, mutual aid interaction, cooperative interaction, role-play interaction between entities to realize expected teaching effect.

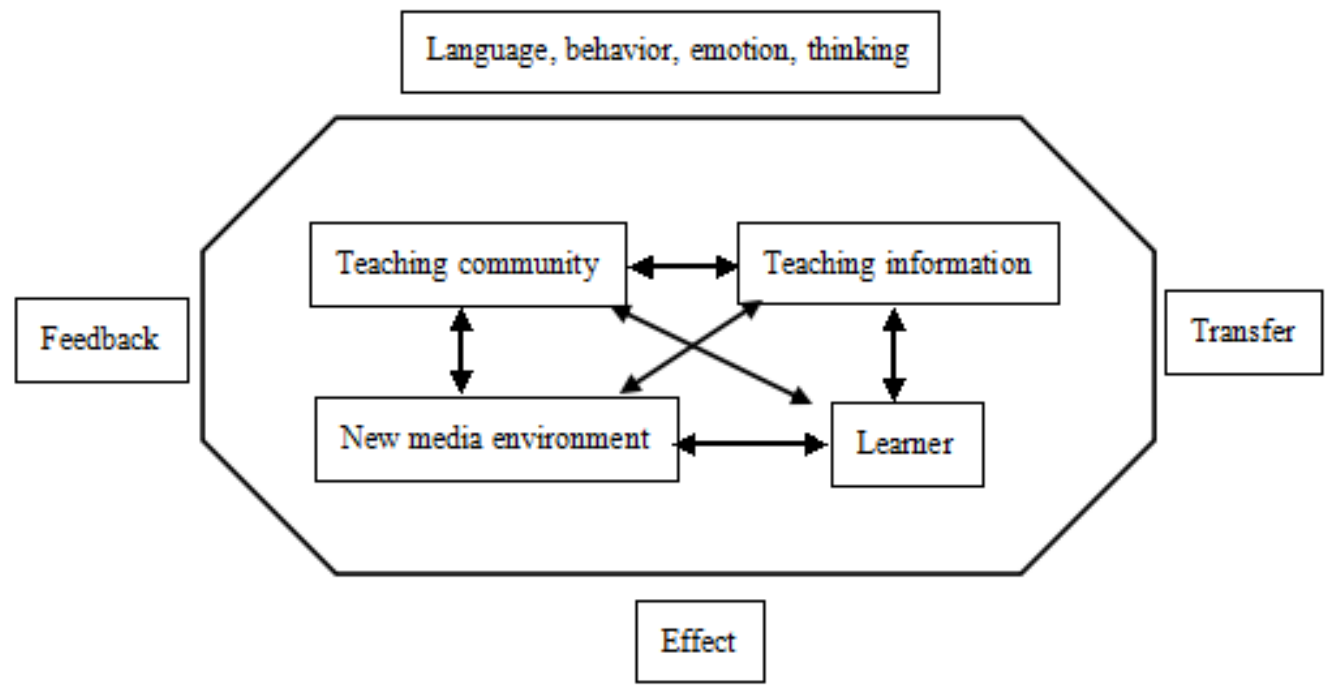

Figure 1. Interaction Structure of Classroom Teaching Under New Media Environment

\subsection{Arts Interactive Teaching Mainly Rely on Computers and Internet}

In interactive teaching primarily achieved through computers and internet, every student has a computer for creative practice, and the interaction happen between teacher, students, and media environment as well. However, the frequency of language and action interaction witnesses obvious decrease, affective and thinking interaction become dominant. With the usage of computers and internet, the interactions can be both real-time and non-real time. As shown in Figure 2, in the interactive teaching process, media environment generally acts as intermediary agent to help achieve 
sharing of information, communication and cooperation between teacher and students, and help both teacher and students to construct, manage, control and display information content.

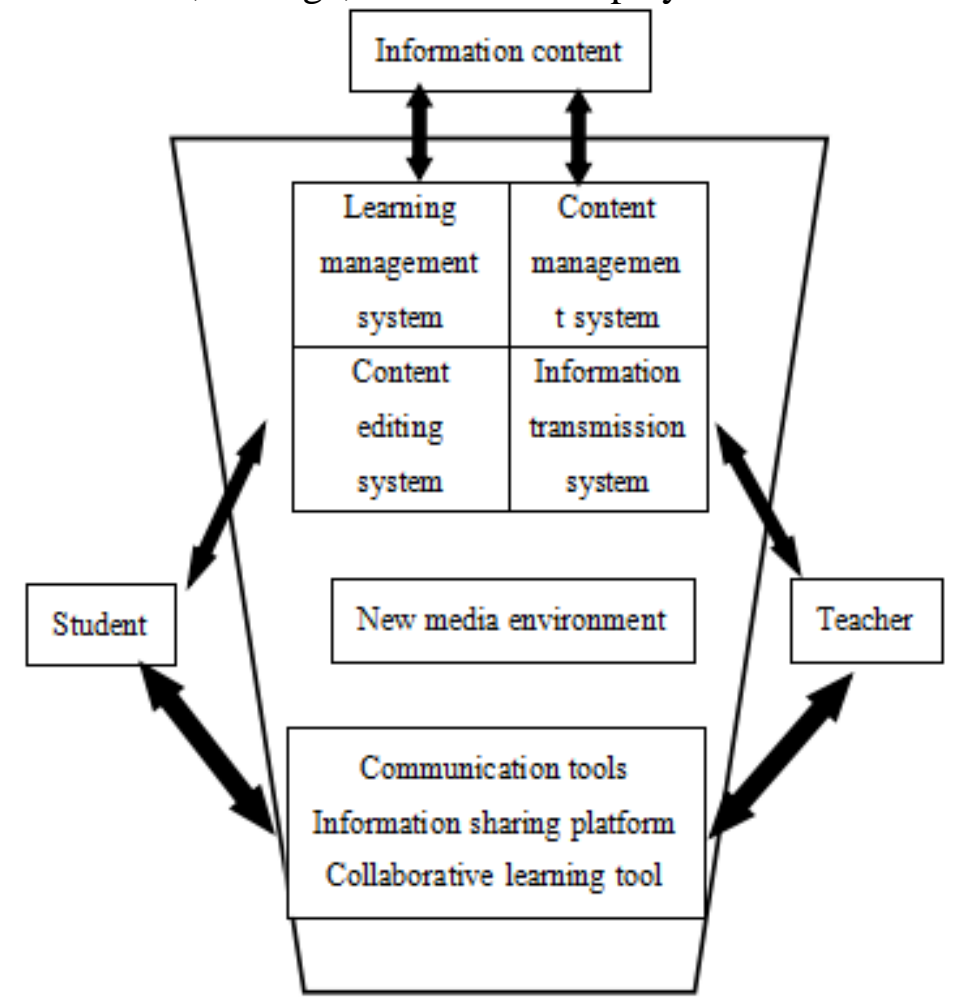

Figure 2. Interactive Structure between Human and New Media Environment in Arts Classroom Teaching

\subsection{New Media Technology's Application in Classroom Teaching}

Applying new media technology to teaching allows teachers to impart much art knowledge and skills possible in limited lecturing time, to better guiding students to appreciate art and to join cultural inheritance and communication for students' personality formation and integrated development. Moreover, the enormous data resource provided on Internet is beneficial to stimulating students' desire for knowledge and to effectively improving teaching efficiency. Teacher's role in teaching process thus changed drastically to authenticator of teaching objective, organizer of teaching process and instructor. For students, the main gain is cultivating favourable behavioral habits.

New media technology offered various methods for teaching demonstration, such as inserting demonstration video, flash, objects projection, Photoshop, to express and appeal to students more powerfully. Methods with good expressive force can boost students' learning initiative to capacity. For example, in previous teaching of Drawing Basics - Composition, the illustrations of composition requirements normally done by drawing at the scene or showing exemplary drawings.

Now teachers can use Photoshop to insert pictures of vegetables, fruits and pots and then explain the requirements of composition via move and free transform function. Reasonable composition of pictures can be show through different kinds of demonstrations. Furthermore, teachers used to paint in the classroom to show students in professional painting training classes. However, due the limitations caused by angles and distances, most students won't be able to fully observer and learn teachers' skills. This problem can be solved by display screen and dv video. Teachers can prepare the $\mathrm{dv}$ machine for a good camera shooting angle, and then connect it to the computer and the display screen. Teachers' whole painting process can be seen clearly in details. In addition, amplifying certain parts of painting is even more convenient for students to learn how to depict details. When in color painting training, turning the screen effect to black and white can help clarify sketch relations for students. 


\section{Conclusion}

Organic integration of new media technology with middle school fine arts teaching brought great vitality, as well as great challenge, to arts interactive teaching. Teachers in arts teaching need to break the old mind-set and make good use of high quality courseware in class for well integration of knowledge and technology to keep up with the development.

\section{Acknowledgment}

Introduced talents start-up capital projects in Wuhan polytechnic university: The augmented reality supported publishing media fusion model in the mobile Internet era. No:20152S05. Humanities and social science project in Hubei province:Origami art innovation application research in the packaging design No:14G234

\section{Reference}

[1]Price, A. 2007. New Media Technologies: Proposing An Integrated Approach. Astronomy Education Review. vol.126, pp171-176.

[2]Narayanan, G. 2006. Crafting change: envisioning new-media arts as critical pedagogy. Leonardo. vol.107, pp373-375.

[3]Jacobson, J. and Hwang, Z. 2002. Unreal Tournament for Immersive Interactive Theater . Communications of the ACM. vol. 45, pp39-42.

[4]Lewis, M and Jacobson, J. 2002. Games Engines in Scientific Research.Communications of ACM, Vol. 45, No. I, vol.143, pp27-31.

[5]Bonet, B. and Geffner, H..2001. Planning as heuristic search. Artificial Intelligence: Special Issue on Heuristic Search, vol.129, pp5-33. 